\title{
Romance and tragedy of tuberculosis: Edward Archibald's contribution to the surgical treatment of pulmonary tuberculosis
}

\author{
Martin A Entin MD \\ Royal Victoria Hospital, Montreal, Quebec
}

\begin{abstract}
Before streptomycin was discovered in 1945, outbreaks of tuberculosis (TB) were responsible for the destruction of the greatest number of people in history. During the 1960s, '70s and '80s, a continuous decline in the incidence of тв in the West created a feeling of complacency which led to the loss of vigilance and of clinical skill in diagnosing it; however, new outbreaks of тв have occurred in the last few years among aboriginals, drug addicts and patients with AIDS. Along with the rise of the incidence of the infection, the resistance of the TB bacilli to known antibiotics has reached alarming levels. Isolation and hospitalization of infected cases is being ordered in large North American cities; a careful search for contacts and close supervision for compliance during periods of treatment are imposed to avoid uncontrolled spread. The World Health Organization reports that a TB epidemic is sweeping through Eastern Europe as part of the global spread of AIDS. Thoracoplasty may have to be considered as a life saving measure for patients whose infection does not respond to any available antibiotic.
\end{abstract}

$\mathrm{T}$ uberculosis (ТВ) has existed from the very dawn of civilization. Records of TB in mummies were found in Egypt as far back as 5000 years ago (1). Although considered by some authorities to be less aggressive than smallpox, the bubonic plague, leprosy or AIDS, TB is responsible for the largest number of deaths in history. It is estimated that one billion people were destroyed by TB in the last two centuries (2).

Known as 'consumption', an appropriate name for this destructive process in the lungs, TB was observed to be passed on from one member of the family to another and from one

Correspondence: Dr Martin Entin, Royal Victoria Hospital, 687 avenue des Pins ouest, Montréal, Québec H3A 1A1.

Telephone 514-842-1231 worker to another in crowded plants. Before discovery of the cause of TB, it was suspected that particles of sputum ejected into the atmosphere by 'open' cases of TB were likely to be aspirated by healthy individuals. Many conditions were thought to be responsible for TB: one was a familial 'weakness'; another was the mythical explanation of 'predisposition'; these were accepted as reality.

The tragedy of $\mathrm{TB}$, apart from the fact that it destroyed large numbers of people, was that the disease frequently affected young adults in the prime of their lives. Greek historian, Herodotus, expressed the situation very poignantly when he said: "in the time of plague it is the parents who bury their children". The young would depart long before they were able to make a contribution to the society.

The subject of TB has been immortalized in the arts and in music. The tragic death of Mimi in Puccini's opera 'La Bohéme', leaves the audience with moist eyes. Everyone is reflecting on the untimely death of this young woman in her mid-20s, but neither the participants in the drama on the stage nor the audience are aware of the wanton spread of bacterialaden particles of sputum that were ejected by the heroine, Mimi, into the atmosphere, contaminating everybody in that area.

In the advanced cases of pulmonary $\mathrm{TB}$, the final months of disease were devoid of hope: symptoms of nightly sweats, chills, continuous paroxysmal cough, progressive loss of flesh and sometimes spread of infection to other organs was devastating. The final stage of the disease arrived when a vessel was eroded by the disease process and hemorrhage within the lungs produced the agonal death.

One could imagine that similar circumstances were responsible for the death of James McGill's adopted daughter. McGill, the founder of McGill University, reported in his journal the culmination of months of hopeless vigilance. His entry is almost laconic: "At 2:00 am on July 4, 1812, my adopted daughter died of decay". The term 'decay' was substituted for the more common expression of 'consumption' (3).

Koch's discovery, in 1882, that the cause of Тв was a bac- 
terial infection, and the subsequent findings that tiny globules of secretion expelled from lung cavities contained live bacteria, solved the mystery of the 'epidemic spread of consumption' among crowded sections of the population. Obligatory isolation of patients with TB was instituted only in this century.

Notwithstanding numerous remedies proffered by physicians over the millennia, there was no definite treatment for TB. Fortunately, natural resistance to TB contamination prevented development of clinical disease in the majority of individuals in the Western population. About $20 \%$ of patients who contracted active TB would recover spontaneously from the illness with the help of natural resistance.

The majority of patients with TB, before antibiotics, would be at the mercy of the advancing disease. Before the discovery of artificial pneumotherapy and thoracoplasty, the patients with advancing disease merely languished, awaiting death.

A glimmer of hope appeared in 1832, when an English physician, James Carson, demonstrated in animals that injection of air into the pleural space collapsed the diseased lung, permitting it to heal (4). This method was put into practice 50 years later when Forlanini rediscovered the process in 1882 (5). This treatment, which was called artificial pneumothorax, produced collapse of the affected lung, putting it 'at rest' and enabling the tuberculous cavities to heal. Unfortunately, in advanced stages of TB, the pleural space itself was obliterated by the invasion of the disease process. In such cases the elastic lung was held stretched, preventing healing; artificial pneumothorax was not possible. The patient would be 'consumed' by the inexorable advance of the disease.

Such was the state of treatment of TB in 1912 when a young Canadian surgeon, Edward Archibald, on the staff at the Royal Victoria Hospital in Montreal, began his active interest in TB. Archibald's forebears came from Scotland. Archibald was born in Montreal in 1872 and attended McGill University, receiving a degree in arts in 1892 and in medicine in 1896. He completed postgraduate training with von Mikulicz in Breslau who convinced him that surgery must be founded on basic science.

On his return to Montreal, he developed тв and was treated at the Saranac Lake Sanatorium for over a year. After his recovery, he married Agnes Barron and joined the Royal Victoria Hospital as assistant surgeon. From the very start of his surgical practice, Archibald became involved in the treatment of 'affections of the head', including acute injuries. He published a monograph on that subject in 1908. Archibald accepted Mikulicz's teaching of the importance of basic science and applied it to his daily practice. He pursued research in respiratory physiology and acute pancreatitis, a condition which was challenging to surgeons. At the annual meeting of the Canadian Society of Clinical Surgeons held in 1909 at the old Toronto General Hospital, young Archibald challenged the senior surgeons of McGill and Toronto universities to apply scientific method in their practice of surgery rather than rely on 'empirical trials'.

WE Gallie, who was a junior member of Professor LH
Cameron's staff, was invited as a guest to that meeting and reported the event with great candor:

\section{"Archibald's skilful direction of the discussion changed the character of surgical education in this country from the purely clinical to the scientific. The impression he left on me that day has remained with me ever since, that familiarity with basic medical science is fundamental... My personal gratitude to him for the vision he disclosed to me is beyond words" (6).}

The incidence of infection was very high in the Quebec province where overcrowding and lack of obligatory milk pasteurization caused the highest mortality in North America (200 per 100,000) (7). Archibald was a consultant to the Trudeau Sanatorium in Saranac Lake, New York, where a number of patients were languishing with chronic and advanced $\mathrm{TB}$, with very little hope of recovery.

There were reports from Europe stating that a promising surgical treatment was being developed. A German chest surgeon, Sauerbruch, a pupil of Mikulicz with whom Archibald had studied in 1900, devised a method of putting the affected lung at rest when artificial pneumothorax was not possible. The method involved collapsing the rib cage by removing portions of the upper ribs on one side, causing the affected lung to collapse. The procedure was called extrapleural thoracoplasty (8).

In 1912, Archibald carried out his first thoracoplasty on a very ill patient. His first two cases did not succeed, and the subsequent attempts were interrupted by World War I (9). When Archibald returned from his military service, he resumed extrapleural thoracoplasty and in time developed improved techniques which offered the chance of arrest of the disease for carefully selected cases. The technique involved adjustment of the length of the resected ribs for the individual needs; doing the procedure in two or three stages; the use of a special endotracheal tube to prevent spilling of infected material into the healthy lung; freeing of the apex of the lung and insertion of a 'living pedicle' of pectoralis muscles to eliminate the empty space.

\section{VASCULAR FLAPS FOR APICOLYSIS}

Archibald's knowledge of respiratory physiology acquired in laboratory experiments helped him in achieving the maximum collapse of the diseased lung. One of the areas that restricted the complete collapse was the apical portion of the lung, which was difficult to approach, and which was prevented from collapsing by intimate attachment to the uppermost ribs and fascia.

He used the approach suggested by C Semb, a Scandinavian surgeon, which facilitated the freeing of the apical lung (10). Archibald was disturbed by the complications that developed due to large collections of blood from the small oozing vessels in the empty space. This served as a nidus for persistant infection in an area to which access was difficult.

Archibald resolved the problem of a large empty apical 


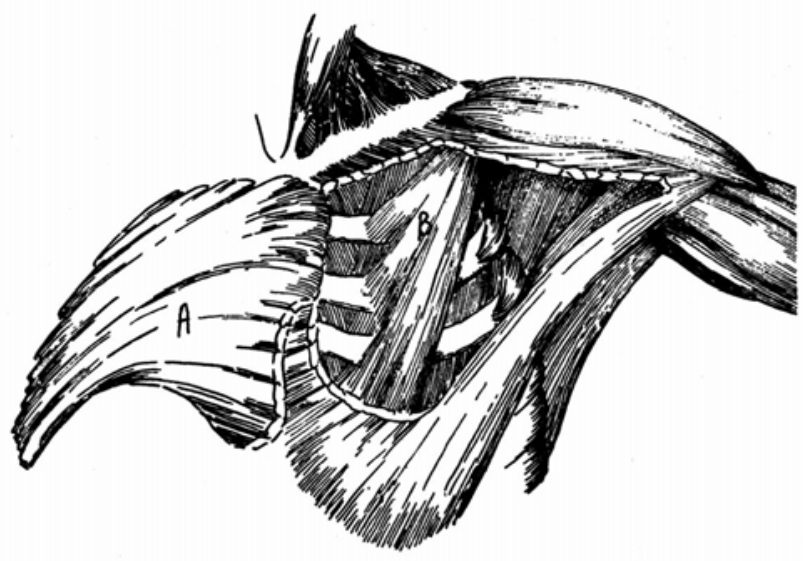

Figure 1) Pectoralis major muscle flap (A) reflected medially, still retaining its sternal blood supply. Pectoralis minor is not yet elevated $(B)$. Reproduced with permission from Archibald (11)

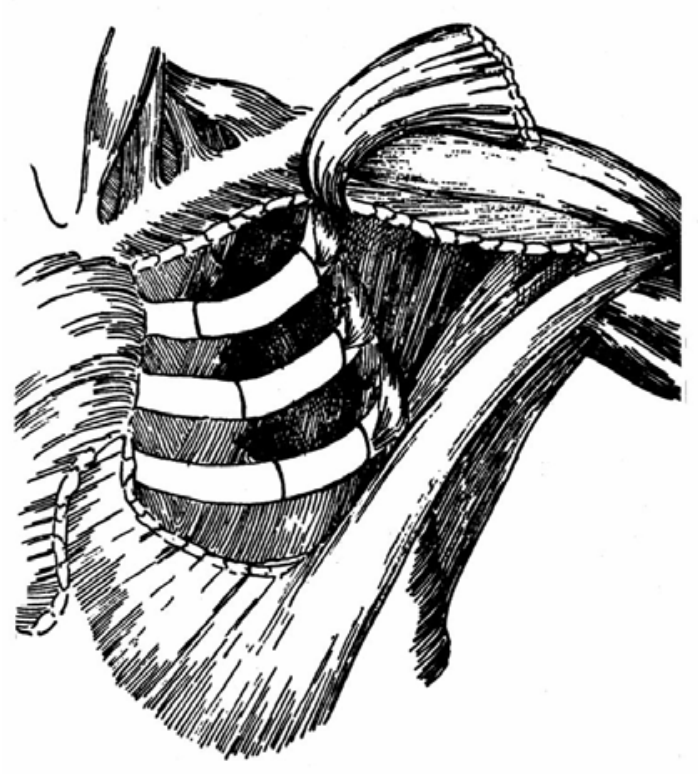

Figure 2) Pectoralis minor muscle is reflected on its thoraco-acromial vascular supply. The second, third and fourth ribs will be removed subperiostially as part of extrapleural collapse of the rib cage for thoracoplasty. Reproduced with permission from Archibald (11)

space by forming a sternally based pedicle from the pectoralis major muscle (Figure 1) and another pedicle from the pectoralis minor muscle, based on its thoraco-acromial attachment (Figure 2). This exposure permitted easy access to separating the upper lobe of lung outside the parietal pleura (Figure 3). When dissection was completed, the two muscle pedicles with the intact blood supply were rotated into the empty apical space, filling it with 'living tissue' that could resist invasion by bacteria (11).

Archibald achieved good results by using the apicolysis of

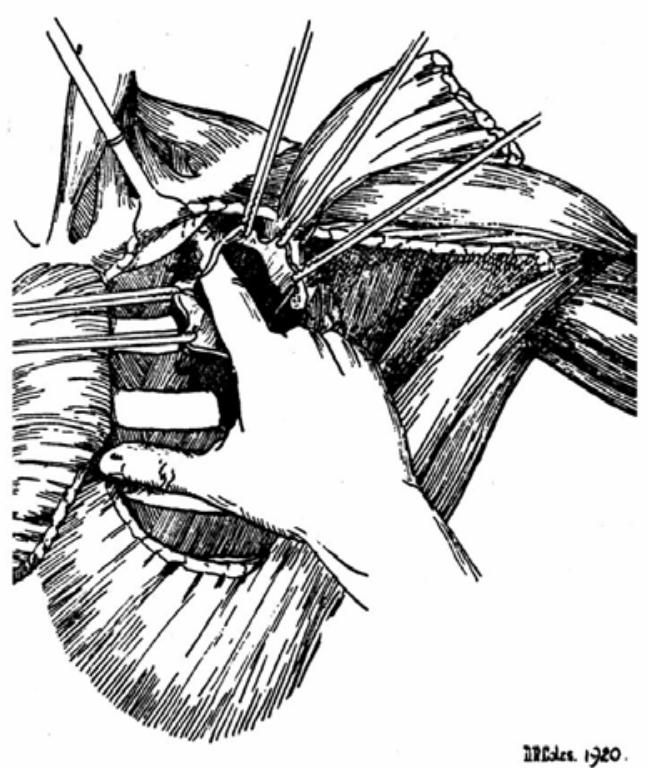

Figure 3) Beginning of separation of the 'apical' lobe of lung outside of the parietal pleura. Sections of second, third and fourth ribs have been removed. The muscle pedicles will be 'packed' into the empty apical space. Reproduced with permission from Archibald (11)

the upper lobe as an adjuvant to thoracoplasty. The procedure became reliable and reproducible because it required considerably less surgical risk. Archibald began to use apicolysis as the 'first stage' in the treatment of patients who were too ill to withstand the classical thoracoplasty. Their improvement after apicolysis permitted carrying out formal thoracoplasty in two or three stages.

Ingenious as Archibald's innovative procedure was, and as helpful as it was for critically ill patients with advanced TB, it did not create a rush of application by other surgeons in other parts of the body or to other infective processes.

Daniel and his associates established the principles and physiology of designing skin flaps which have become the basis of reconstruction and replacement in loss of tissue (12). The classification of muscle pedicles and free muscle flaps was assembled into a very useful clinical atlas of muscle and musculocutaneous flaps by Mathes and Nahai in 1979 (13). The principle of application of various types of muscle flaps for treatment and prevention of chronic osteomyelitis was formulated by Ger and his associates (14). There were other contributors to this area. Today, almost two generations later, the transposition and transplantation of cutaneous muscle and musculocutaneous flaps is a routine procedure as part of reconstruction in many surgical specialties.

Archibald was the first surgeon in North America to carry out systematic surgical treatment of advanced TB. Until the discovery of streptomycin in 1945, Archibald's procedure offered the only chance for patients with advanced TB to attain control of their disease and the opportunity to carry on with a normal and productive life (15). 


\section{REFERENCES}

1. Cave AJE. Evidence of incidence of tuberculosis in ancient Egypt. Br J Tuberculosis 1935;33:142-52.

2. Ryan F. Tuberculosis: The Greatest Story Never Told. Bromsgrove, Worcestershire, UK: Swifth Publishers, 1992.

3. Journal of James McGill. McGill Archives, McGill University, Montreal.

4. James Carson, 1820. In: Moriston Davies, Pulmonary Tuberculosis. Medical and Surgical Treatment, London, 1933.

5. Forlanini C. Deutsche Medizinsche Wocheschrifs, 1906. Tuberculosis 1934;16:121.

6. Gallie WE. Appreciation to Dr Archibald. Can Med Assoc J 1946;154:197.

7. Comstock GW. Advances toward the conquest of tuberculosis. Public Health Report 1980;25:444.
8. Sauerbruch's Method. In: Archibald, E. Recent advances in thoracic surgery. Can Med J 1924;14:240.

9. Archibald E. The present status of surgery in pulmonary tuberculosis. Can Med Assoc J 1913;3:1087.

10. Semb C. Thoracoplasty with extrafascial apicolysis. Acta Chir Scand 1935;76:84.

11. Archibald E. Extrapleural thoracoplasty. Am Rev Tuberculosis 1921;4:828.

12. Damel RK, Kerrigan CL. In: Principles and Physiology of Skin Flaps in Plastic Surgery. Philadelphia: WB Saunders, 1990: 275-328.

13. Mathe SJ, Nahai F. Clinical Atlas of Muscle and Musculocutaneous Flaps. St Louis: CV Mosby Co, 1979.

14. Ger R. Muscle transposition for treatment and prevention of chronic post-traumatic osteomyelitis of the tibia. J Bone Joint Surg 1977;59A:784.

15. Entin MA. Dr Edward W Archibald - A biographical sketch. Montreal: Medico Chirurgical Society Newsletter, 1990:6. 